\title{
Propofol promotes apoptosis and suppresses the HOTAIR-mediated mTOR/p70S6K signaling pathway in melanoma cells
}

\author{
ZHIWEI SHANG, HAIXIA FENG, LISHA CUI, WEIPING WANG and HONGWEI FU \\ Department of Dermatology, The First Affiliated Hospital of Henan University of Science and Technology, \\ Luoyang, Henan 471003, P.R. China
}

Received December 7, 2015; Accepted June 29, 2017

DOI: $10.3892 / 01.2017 .7297$

\begin{abstract}
Propofol is an intravenous anesthetic, which is widely used in clinical anesthesia induction and maintenance and is critical in the sedation of patients. However, the functions and mechanisms of propofol on apoptosis of melanoma cells remain unclear. The present study investigated whether propofol promotes cell apoptosis and suppresses the HOX transcript antisense RNA (HOTAIR)-mediated mechanistic target of rapamycin (mTOR) pathway in melanoma cells. B16F10 cells were cultured with different concentrations $(0-10 \mu \mathrm{M})$ of propofol for 24 or $48 \mathrm{~h}$. Proliferation and apoptosis of B16F10 cells were detected using MTT assay and flow cytometry. The pcDNA 3.1(-)-HOTAIR and pcDNA 3.1(-)-control plasmids were transfected into B16F10 cells using Lipofectamine 2000. In the present study, treatment with propofol significantly reduced viability, and induced apoptosis and caspase- 3 activity in melanoma cells. Propofol treatment significantly inhibited HOTAIR expression and the expression of phosphorylated (p)-mTOR and p- p70S6K protein in melanoma cells. Overexpression of HOTAIR significantly increased viability of melanoma cells, and increased HOTAIR, p-mTOR and p-p70S6K protein expression in melanoma cells. These results indicated that propofol promotes apoptosis and suppresses the HOTAIR-mediated mTOR signaling pathway in melanoma cells.
\end{abstract}

\section{Introduction}

Although the morbidity of malignant melanoma only contributes to $1 \%$ of skin neoplasms, its mortality rate is the highest

Correspondence to: Mr. Zhiwei Shang, Department of Dermatology, The First Affiliated Hospital of Henan University of Science and Technology, 24 Jinghua Road, Jianxi, Luoyang, Henan 471003, P.R. China

E-mail: 1ijunhai666342851@163.com

Key words: propofol, melanoma, HOX transcript antisense RNA, mechanistic target of rapamycin of all skin neoplasms, mainly due to its high potential to metastasize to vital organs in 2010 in China (1). Malignant melanoma accounted for $80 \%$ of skin neoplasm-associated mortalities in 2012 in China (1,2). There is a rising trend in the number of melanoma cases worldwide (3). Among the industrial cities in South China, the morbidity of melanoma is much higher compared with the Chinese average rate, due to complex environmental factors (4).

Gupta recently reported that HOX transcript antisense RNA (HOTAIR) performs an important role in breast cancer metastasis with high expression in metastatic breast cancer tissues (5). In addition, high HOTAIR expression in primary breast cancer tissues can be used to predict tumor metastasis and mortality with a good accuracy (6). These studies indicated that long non-coding RNAs, such as HOTAIR, are involved in tumor formation and progression (6).

Propofol is a fast and short-acting intravenous anesthetic, which is widely used in the induction and maintenance of various clinical surgeries $(7,8)$. In addition, since propofol is also used in intensive care patients and with other clinical sedative treatment (9). Propofol has a number of characteristics that make it advantageous as an anesthetic, including taking effect quickly, short metabolic time, easy control of narcosis and slight adverse reactions. However, propofol has a number of non-narcotic effects (10), for example, sub-hypnotic doses of propofol cause forgetfulness and inhibit anxiety. When used for anesthetic introduction and maintenance, propofol can reduce the incidence of nausea and vomiting following surgery (11). Furthermore, small doses of propofol can be directly used to treat nausea and vomiting following surgery. Propofol can adjust the activity of cytotoxic T lymphocytes to increase their antitumor activity and immune regulation (12). In the present study, the anticancer effects of propofol on cell apoptosis of melanoma cells were investigated, and the underlying mechanism was investigated.

\section{Materials and methods}

Cell culture. The murine melanoma B16F10 cell line was purchased from the Cell bank of Chinese Academy of Sciences (Shanghai, China). B16F10 cells were cultured in complete growth RPMI-1640 medium (Thermo Fisher Scientific, Inc., 
Waltham, MA, USA) supplemented 10\% heat-inactivated fetal bovine serum (Gibco; Thermo Fisher Scientific, Inc.) and 1\% penicillin/streptomycin (Gibco; Thermo Fisher Scientific, Inc.) at $37^{\circ} \mathrm{C}$ in a humidified $5 \% \mathrm{CO}_{2}$ atmosphere.

Cell proliferation analysis by MTT assay. Cell proliferation of murine melanoma B16F10 cells was determined by MTT assay kit (Beyotime Institute of Biotechnology, Haimen, China) according to the manufacturer's protocol. B16F10 cells $\left(1 \times 10^{4}\right)$ were plated on 96-well culture plates and co-cultured with different concentrations $(0-10 \mu \mathrm{M})$ of propofol (Sigma-Aldrich; Merck KGaA, Darmstadt, Germany; Fig. 1) for 24 or $48 \mathrm{~h}$ at $37^{\circ} \mathrm{C}$. MTT stock solution $(20 \mu \mathrm{l} ; 5 \mathrm{mg} / \mathrm{ml})$ was supplemented and cultured at $37^{\circ} \mathrm{C}$ in a humidified $5 \% \mathrm{CO}_{2}$ atmosphere for $4 \mathrm{~h}$. Dimethyl sulfoxide (200 $\mu \mathrm{l}$; Invitrogen; Thermo Fisher Scientific, Inc.) was added to dissolve the precipitate. Absorbance was detected at $570 \mathrm{~nm}$ by Multiskan Spectrum (Thermo Fisher Scientific, Inc.).

Detection of cell apoptosis. B16F10 cells $\left(1 \times 10^{6}\right)$ were plated on 6-well culture plates and co-cultured with different concentrations (0-10 $\mu \mathrm{M})$ of propofol (Sigma-Aldrich; Merck KGaA) for 24 or $48 \mathrm{~h}$ at $37^{\circ} \mathrm{C}$. Apoptosis of murine melanoma B16F10 cells was determined using Annexin V-fluorescein isothiocyanate (FITC)/propidium iodide (PI) (Vybrant; Invitrogen; Thermo Fisher Scientific, Inc.). Annexin V-FITC (100 $\mu \mathrm{l})$ and $5 \mu 1$ PI were added to each well for $15 \mathrm{~min}$ at room temperature and analyzed by flow cytometry (FACSCanto II; BD Biosciences, Franklin Lakes, NJ, USA), using FlowJo software 7.6.1 (Tree Star, Inc., Ashland, OR, USA).

B16F10 cells $\left(1 \times 10^{4}\right)$ were plated on 96-well culture plates and co-cultured with different concentrations $(0-10 \mu \mathrm{M})$ of propofol (Sigma-Aldrich; Merck KGaA; Fig. 1) for 24 or $48 \mathrm{~h}$ at $37^{\circ} \mathrm{C}$. Caspase-3 substrate Ac-DEVD-pNA (10 $\mu \mathrm{l}$; cat. no. C1115; Beyotime Institute of Biotechnology) was added to each well of a 96 -well plate for $6 \mathrm{~h}$ at $37^{\circ} \mathrm{C}$. The control group was the equivalent B16F10 cells treated with vehicle. The caspase- 3 activity was detected at $405 \mathrm{~nm}$ by Multiskan Spectrum (Thermo Fisher Scientific, Inc.).

Plasmid constructs and transfection. The pcDNA 3.1(-)HOTAIR and pcDNA 3.1(-)-control plasmids were prepared by Sangon Biotech Co. Ltd. (Shanghai, China). The pcDNA 3.1(-)HOTAIR (50 ng) and pcDNA 3.1(-)-control plasmids (50 ng) were transfected using Lipofectamine 2000 (Invitrogen; Thermo Fisher Scientific, Inc.) according to the manufacturer's protocol. Experiments were conducted following transfection for $48 \mathrm{~h}$ in vitro at $37^{\circ} \mathrm{C}$.

Western blot analysis. B16F10 cells $\left(1 \times 10^{6}\right)$ were incubated on 6-well culture plates and co-cultured with different concentrations (0-10 $\mu \mathrm{M})$ of propofol (Sigma-Aldrich; Merck KGaA) for 24 or $48 \mathrm{~h}$. The total protein from cervical cancer cells was isolated using radioimmunoprecipitation assay lysis buffer (Beyotime Institute of Biotechnology) with protease or phosphatase inhibitors (Beyotime Institute of Biotechnology). The protein concentration was quantified using bicinchoninic acid protein assay kit (Beyotime Institute of Biotechnology). Total protein $(50 \mu \mathrm{g})$ was loaded onto $10-1210 \%$ SDS-PAGE and transferred to polyvinylidene fluoride (PVDF) membranes (Bio-Rad Laboratories, Inc., Hercules, CA, USA). PVDF

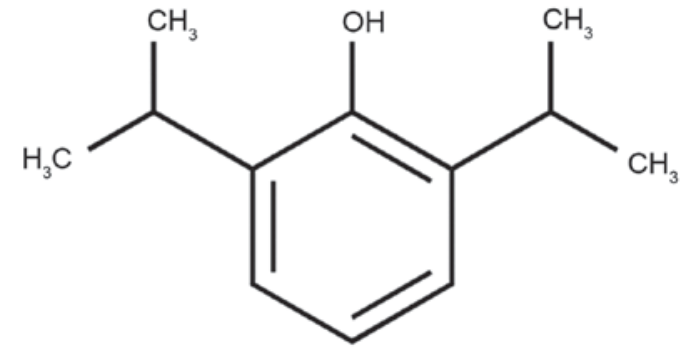

Figure 1. Chemical structure of propofol.

membranes were blocked with $5 \%(\mathrm{w} / \mathrm{v})$ skim milk in TPBS (0.05\% Tween-20) at $37^{\circ} \mathrm{C}$ for $1 \mathrm{~h}$ and incubated with primary antibodies: Anti-HOTAIR, anti-phosphorylated (p)-mTOR (sc-101738, 1:500; Santa Cruz Biotechnology, Inc., Dallas, TX, USA), anti-p-70 kDa ribosomal protein S6 kinase (p70S6K, sc-9027, 1:500; Santa Cruz Biotechnology, Inc.) and $\beta$-actin (sc-7210, 1:500; Santa Cruz Biotechnology, Inc.) for $12 \mathrm{~h}$ at $4^{\circ} \mathrm{C}$. Subsequent to washing with TPBS, membranes were incubated with anti-IgG conjugated with horseradish peroxidase antibody (sc-2004, 1:5,000; Santa Cruz Biotechnology, Inc.) at $37^{\circ} \mathrm{C}$ for $1 \mathrm{~h}$ and detected under a chemiluminescence detection system (UVItec, Cambridge, UK).

Statistical analysis. SPSS 17.0 performed the statistical analysis. (SPSS, Inc., Chicago, IL, USA) and performed with one-way analysis of variance followed by Scheffe's post hoc test. All values are expressed as the mean \pm standard deviation. $\mathrm{P}<0.05$ was considered to indicate a statistically significant difference.

\section{Results}

Propofol suppresses melanoma cell growth. The effect of propofol on melanoma cell growth was assessed using the recommended concentrations $(0-10 \mu \mathrm{M})$, and cell proliferation was analyzed by MTT assay. The results showed that treatment with 5 or $10 \mu \mathrm{M}$ of propofol significantly suppressed melanoma cell growth in a dose- and time-dependent manner compared with no treatment (Fig. 2).

Propofol promotes apoptosis of melanoma cells. Melanoma B16F10 cells were treated with different concentrations (0-10 $\mu \mathrm{M})$ of propofol, and apoptosis was detected. As shown in Fig. 3, treatment with 5 or $10 \mu \mathrm{M}$ propofol significantly promoted apoptosis of melanoma cells in a dose-dependent manner compared with no treatment.

Propofol promotes caspase-3 activity in melanoma. The antitumor activity of propofol on caspase-3 activity in melanoma was evaluated. Melanoma B16F10 cells were incubated with 0-10 $\mu \mathrm{M}$ propofol, and caspase-3 activity was found to be significantly increased in the 5 or $10 \mu \mathrm{M}$ propofol groups compared with the $0 \mu \mathrm{M}$ propofol treatment (Fig. 4).

Propofol suppresses the level of HOTAIR, p-mTOR and $p$-p70S6K protein expression in melanoma. It was examined whether propofol-induced apoptosis is associated with alterations of HOTAIR signaling pathways in melanoma cells. Data obtained from western blot analysis (Fig. 5) demonstrated 


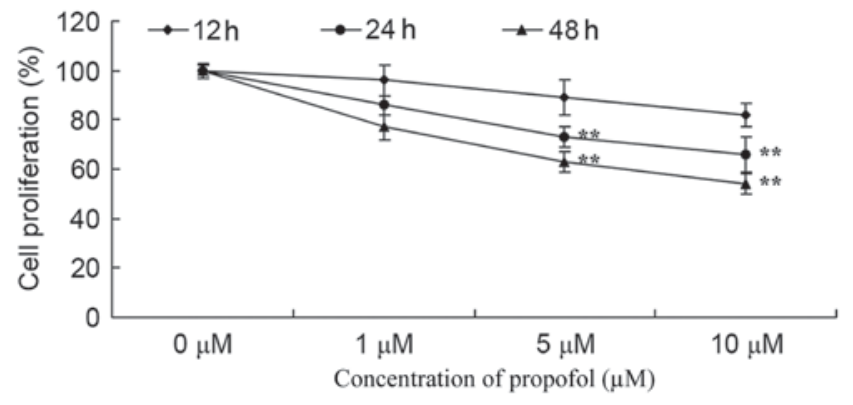

Figure 2. Propofol suppresses melanoma cell growth. ${ }^{* *} \mathrm{P}<0.01$ vs. no treatment.

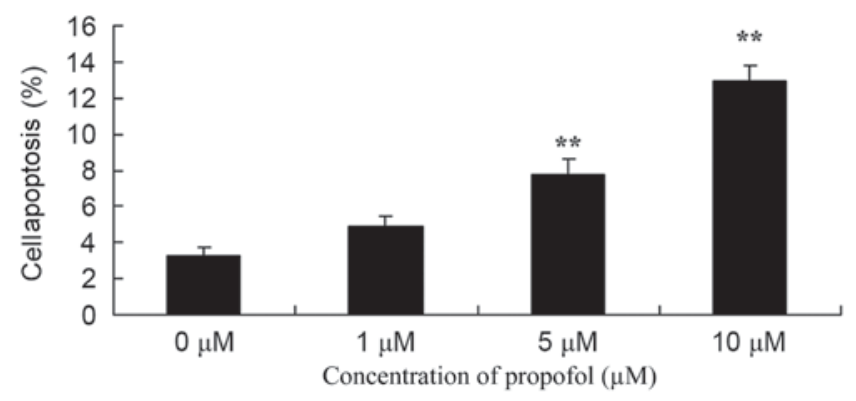

Figure 3. Propofol promotes apoptosis in melanoma cells. ${ }^{* *} \mathrm{P}<0.01$ vs. no treatment.

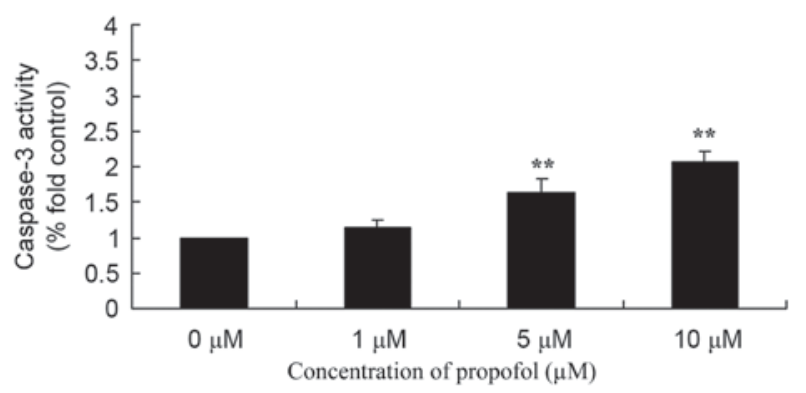

Figure 4. Propofol promotes caspase- 3 activity in melanoma. ${ }^{* *} \mathrm{P}<0.01$ vs. no treatment.

that 5 or $10 \mu \mathrm{M}$ propofol suppressed the level of HOTAIR, $\mathrm{p}-\mathrm{mTOR}$ and $\mathrm{p}-\mathrm{p} 70 \mathrm{~S} 6 \mathrm{~K}$ protein expression in B16F10 cells compared with no treatment.

HOTAIR overexpression suppresses the anti-cancer effect of propofol on melanoma cell growth by altering the expression of HOTAIR, $p$-mTOR and p-p70S6K. To address the mechanism of how propofol triggers the activation of HOTAIR signaling pathways, B16F10 cells were transfected with HOTAIR plasmids. B16F10 cells transfected with HOTAIR plasmids significantly decreased the level of protein HOTAIR, p-mTOR and p-p70S6K expression in melanoma (Fig. 6A-D). Notably, HOTAIR overexpression was able to suppress the anti-cancer effect of propofol $(5 \mu \mathrm{M})$ on B16F10 cell growth (Fig. 6E).

\section{Discussion}

Melanoma, also termed malignant melanoma, is a common skin neoplasm caused by hyperplasia of abnormal melanocytes (13). Although China is one of the countries with a low incidence of melanoma, the growth rate of malignant melanoma has continued to increase over previous years (14). Due to the early metastasis, fast progression, poor prognosis and high mortality rate of malignant melanoma, there is still no favorable drug to cure melanoma (15). With research and development of Chinese herbal medicinal ingredients as anticancer drugs, a number of active ingredients in Chinese herbs have reached good efficacy in clinical anticancer experiments, which provided new direction in melanoma drug therapy research (16). Zhang et al (17) reported that propofol significantly inhibited viability and increased apoptosis of cervical cancer cells through suppression of the HOTAIR-mediated mTOR signaling pathway.

In the present study, the results showed that treatment with propofol was able to significantly suppress growth, and promote apoptosis and caspase-3 activity in melanoma cells. Taken together, these data demonstrated the ability of propofol to suppress melanoma, but the underlying mechanism requires additional study.

HOTAIR is a non-coding RNA containing 231 nucleotides, which is associated with the human HOX locus and promoted the metastasis of breast cancer (6). A study verified that HOTAIR has the capacity to induce the metastasis of numerous tumors (18).

In order to verify whether HOTAIR is able to promote melanoma progression, a series of in vitro functional experiments were previously conducted by the present authors, with the scratch test introducing HOTAIR-knockout to inhibit the metastasis of melanoma, and Matrigel invasion test showing that the invasion of melanoma cells is dependent on whether HOTAIR is expressed (5). The expression of HOTAIR in hepatocellular carcinoma is high and close to non-tumor tissues, which indicates that the expression of HOTAIR in hepatocellular carcinoma is associated with lymph node metastasis (19). In a previous study, which knocked out HOTAIR in hepatocellular carcinoma cells, it was found that matrix metalloproteinase-9 (MMP-9) was also knocked out, which indicated that MMP-9 is likely to be involved in the regulation of hepatocellular carcinoma progression (20). In the present study, propofol suppressed HOTAIR protein expression and overexpression of HOTAIR suppressed the anticancer effect of propofol on melanoma cell growth. The present study reported a potential role of HOTAIR in the regulation of propofol-induced apoptosis of melanoma B16F10 cells.

The phosphoinositide 3-kinase (PI3K)/Akt/mTOR signal transduction pathway consists of three proteases, including PI3K, Akt and mTOR (21). The activation of the $\mathrm{PI} 3 \mathrm{~K} / \mathrm{Akt} / \mathrm{mTOR}$ signal transduction pathway can inhibit triggers of apoptosis by numerous types of stimuli, and promote cell cycle progression, survival and proliferation of tumor cells $(22,23)$. The PI3K/Akt/mTOR signaling pathway also has several other functions, including involvement in angiogenesis and in the occurrence, development and drug resistance of malignant tumor, and also tumor invasion and metastasis $(22,23)$. The present study demonstrated that propofol significantly suppressed the level of p-mTOR protein expression, and overexpression of HOTAIR significantly increased mTOR protein expression in melanoma B16F10 cells. Chang et al (7) reported that propofol induced autophagy and 
A
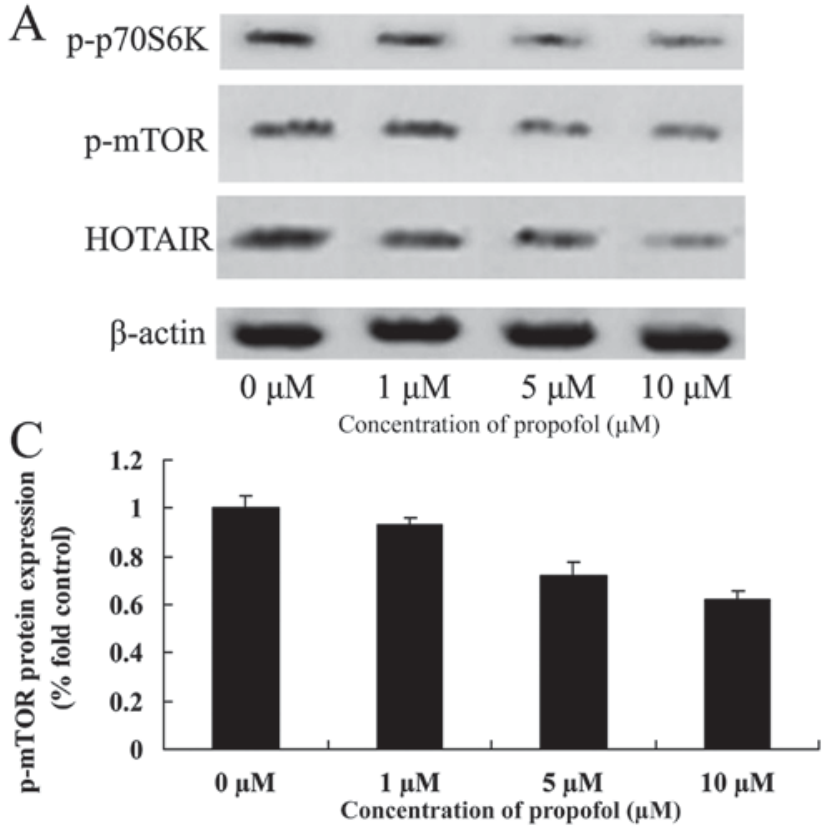

$\mathrm{B}$

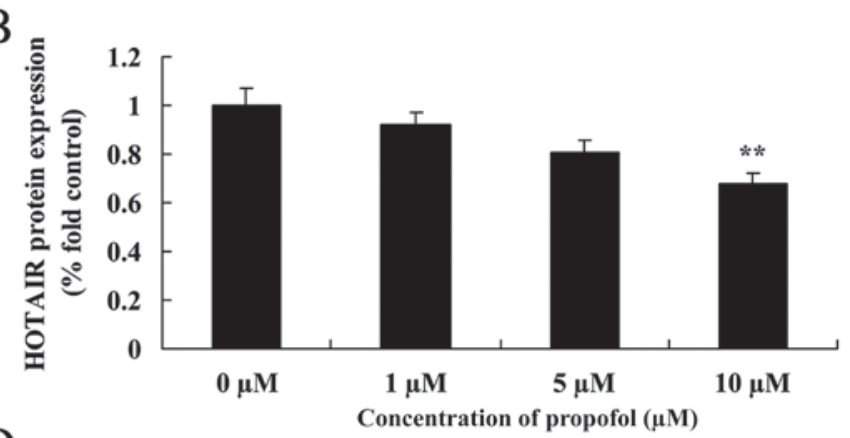

$\mathrm{D}$

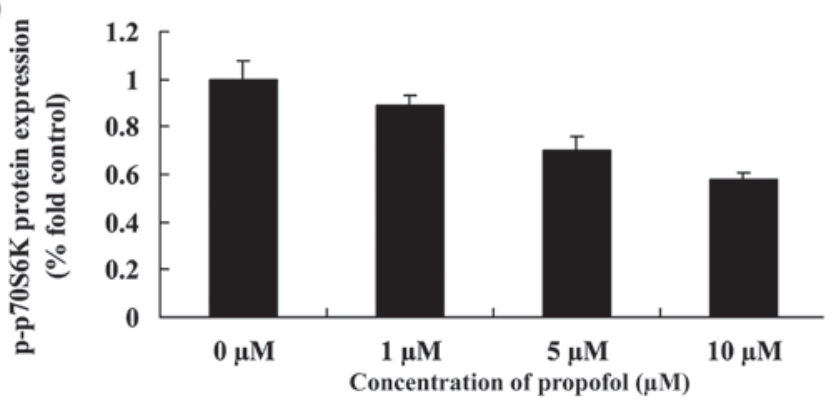

Figure 5. Propofol suppresses HOTAIR, p-mTOR and p-p70S6K protein expression in melanoma. (A) Western blot analysis and statistical analysis of (B) HOTAIR, (C) p-mTOR and (D) p-p70S6K protein expression in melanoma. ${ }^{* *} \mathrm{P}<0.01$ vs. no treatment. HOTAIR, HOX transcript antisense RNA; mTOR, mechanistic target of rapamycin; p-, phosphorylated.
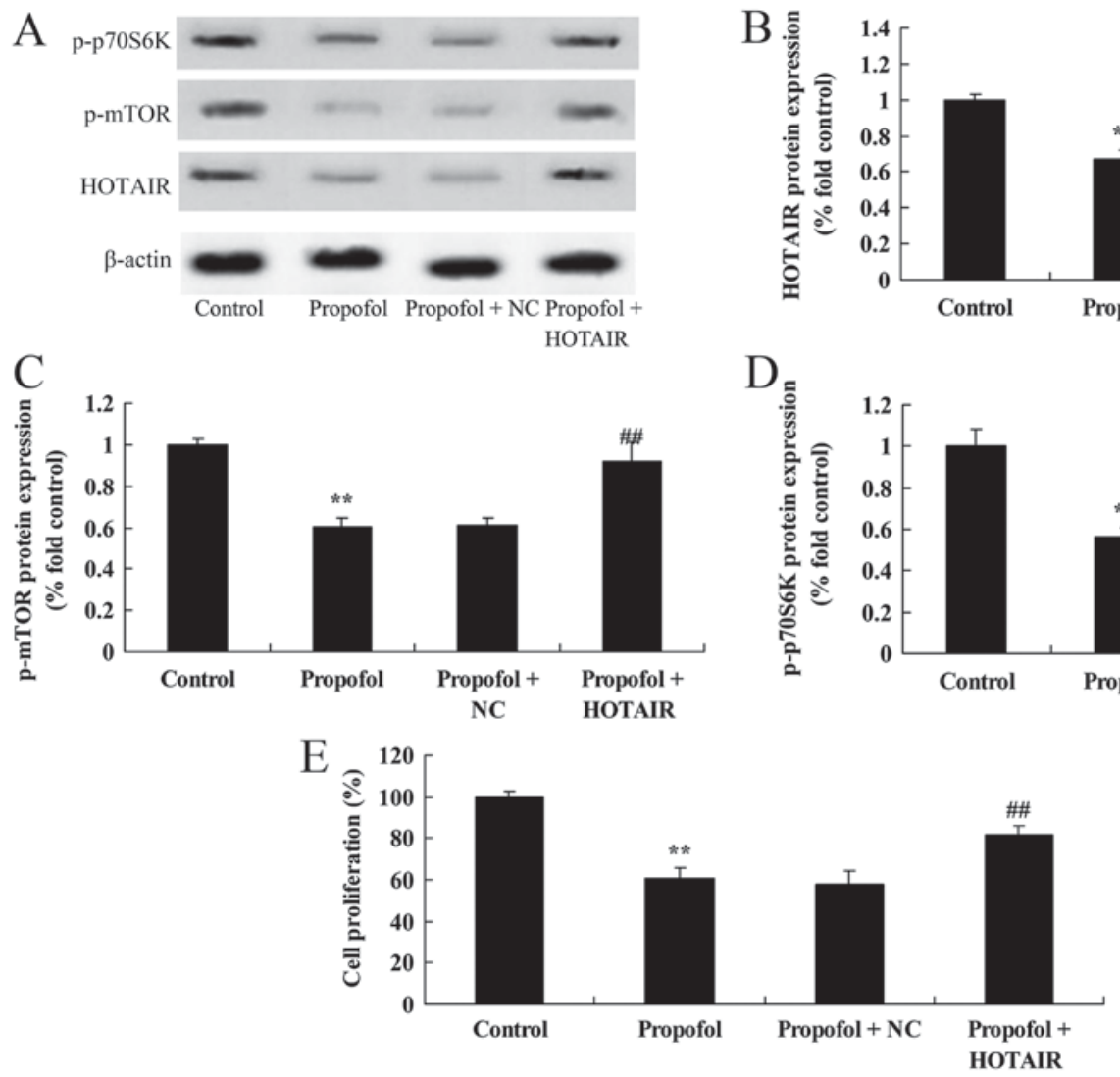
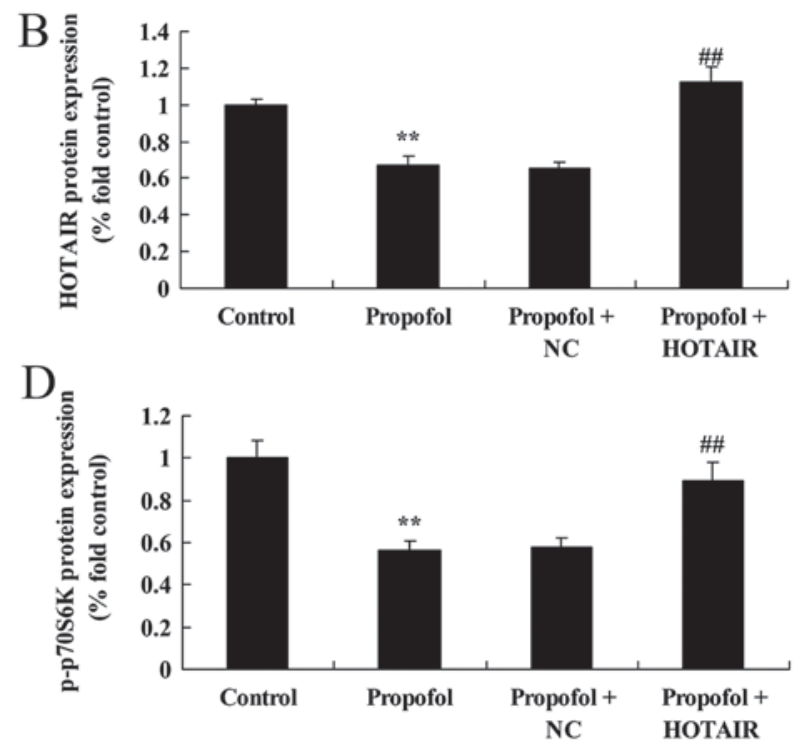

HOTAIR

Figure 6. HOTAIR overexpression suppresses the anticancer effect of propofol on melanoma cell growth by altering the expression of HOTAIR, p-mTOR and p-p70S6K proteins. (A) Western blot analysis and statistical analysis demonstrated that HOTAIR overexpression increased the level of (B) HOTAIR, (C) p-mTOR and (D) p-p70S6K protein expression and (E) suppressed the anticancer effect of propofol on melanoma cell growth. ${ }^{* *} \mathrm{P}<0.01 \mathrm{vs}$. no treatment, ${ }^{\# \#} \mathrm{P}<0.01$ vs. the propofol group. HOTAIR, HOX transcript antisense RNA; NC, negative control; mTOR, mechanistic target of rapamycin; p-, phosphorylated.

increased angiogenic capacity of human umbilical vascular endothelial cells through PI3K/Akt and mTOR.
A previous study indicated that the Akt/mTOR/p70S6K signal transduction pathway is aberrantly activated during 
tumor generation and development (24). Akt/mTOR is regarded as a main signal adjustment pathway of protein synthesis, involved in cell proliferation, differentiation and metastasis (25). mTOR is a multi-functional kinase associated with the regulation of important cellular processes (25). Phosphorylation of p70S6K can promote mRNA translation and the cell cycle (26). Restraining mTOR can lead to blocked p70S6K phosphorylation and translation, thereby causing cell cycle arrest and induction of apoptosis $(27,28)$. Chang et al (7) reported that treatment with propofol induced autophagy and increased angiogenic capacity of human umbilical vascular endothelial cells through PI3K/Akt and mTOR. In the current study, propofol suppressed p70S6K protein expression, and HOTAIR overexpression promoted the anti-cancer effect of propofol on p70S6K protein expression in melanoma cells. Taken together, the present findings indicate the involvement of mTOR and p70S6K in the promotion of propofol-induced apoptosis of melanoma.

The present results indicated that propofol significantly suppresses cell growth, and promotes apoptosis and caspase-3 activity in melanoma. Western blot analysis demonstrated that HOTAIR overexpression suppressed mTOR and p70S6K expression in B16F10 cells following treatment with propofol. Therefore, the main findings of the present study were that propofol promotes apoptosis and suppresses the HOTAIR-mediated mTOR/p70S6K signaling pathway in melanoma cells.

\section{References}

1. Constantinescu R, Elm J, Auinger P, Sharma S, Augustine EF, Khadim L and Kieburtz K; NET-PDInvestigators: Malignant melanoma in early-treated Parkinson's disease: The NET-PD trial. Mov Disord 29: 263-265, 2014.

2. Hiniker SM, Reddy SA, Maecker HT, Subrahmanyam PB, Rosenberg-Hasson Y, Swetter SM, Saha S, Shura L and Knox SJ: A prospective clinical trial combining radiation therapy with systemic immunotherapy in metastatic melanoma. Int J Radiat Oncol Biol Phys 96: 578-588, 2016.

3. Hansson J, Aamdal S, Bastholt L, Brandberg Y, Hernberg M, Nilsson B, Stierner U and von der Maase H; Nordic Melanoma Cooperative Group: Two different durations of adjuvant therapy with intermediate-dose interferon alfa- $2 b$ in patients with high-risk melanoma (Nordic IFN trial): A randomised phase 3 trial. Lancet Oncol 12: 144-152, 2011.

4. Escudier B, Lassau N, Angevin E, Soria JC, Chami L, Lamuraglia M, Zafarana E, Landreau V, Schwartz B, Brendel E, et al: Phase I trial of sorafenib in combination with IFN alpha-2a in patients with unresectable and/or metastatic renal cell carcinoma or malignant melanoma. Clin Cancer Res 13: 1801-1809, 2007.

5. Tang L, Zhang W, Su B and Yu B: Long noncoding RNA HOTAIR is associated with motility, invasion, and metastatic potential of metastatic melanoma. Biomed Res Int 2013: 251098, 2013.

6. Yan R, Cao J, Song C, Chen Y, Wu Z, Wang K and Dai L: Polymorphisms in lncRNA HOTAIR and susceptibility to breast cancer in a Chinese population. Cancer Epidemiol 39: 978-985, 2015.

7. Chang CY, Chen PH, Lu SC, Hsieh MC, Lin CW, Lee HM, Jawan B and Kao YH: Propofol-enhanced autophagy increases motility and angiogenic capacity of cultured human umbilical vascular endothelial cells. Life Sci 142: 49-59, 2015.

8. Glen JB, Hunter SC, Blackburn TP and Wood P: Interaction studies and other investigations of the pharmacology of propofol ('Diprivan'). Postgrad Med J 61 (Suppl 3): S7-S14, 1985.

9. Goudra BG, Singh PM, Gouda G, Borle A, Gouda D, Dravida A and Chandrasekhara V: Safety of non-anesthesia provider-administered propofol (NAAP) sedation in advanced gastrointestinal endoscopic procedures: Comparative meta-analysis of pooled results. Dig Dis Sci 60: 2612-2627, 2015.
10. Orsini J, Nadkarni A, Chen J and Cohen N: Propofol infusion syndrome: Case report and literature review. Am J Health Syst Pharm 66: 908-915, 2009.

11. Habre C, Tramèr MR, Pöpping DM and Elia N: Ability of a meta-analysis to prevent redundant research: Systematic review of studies on pain from propofol injection. BMJ 348: g5219, 2014.

12. Braz MG, Braz LG, Mazoti MA, Pinotti MF, Pardini MI, Braz JR and Salvadori DM: Lower levels of oxidative DNA damage and apoptosis in lymphocytes from patients undergoing surgery with propofol anesthesia. Environ Mol Mutagen 53: 70-77, 2012.

13. Tang Q, Li J, Zhu H, Li P, Zou Z and Xiao Y: Hmgb1-IL-23IL-17-IL-6-Stat 3 axis promotes tumor growth in murine models of melanoma. Mediators Inflamm 2013: 713859, 2013.

14. Li Y, Yuan J, Yang Q, Cao W, Zhou X, Xie Y, Tu H, Zhang Y and Wang S: Immunoliposome co-delivery of bufalin and anti-CD40 antibody adjuvant induces synergetic therapeutic efficacy against melanoma. Int J Nanomedicine 9: 5683-5700, 2014.

15. Guo J, Zhu J, Sheng X, Wang X, Qu L, Han Y, Liu Y, Zhang H, Huo L, Zhang S, et al: Intratumoral injection of dendritic cells in combination with local hyperthermia induces systemic antitumor effect in patients with advanced melanoma. Int J Cancer 120: 2418-2425, 2007.

16. Chen LG, Chang WL, Lee CJ, Lee LT, Shih CM and Wang CC: Melanogenesis inhibition by gallotannins from Chinese galls in B16 mouse melanoma cells. Biol Pharm Bull 32: 1447-1452, 2009.

17. Zhang D, Zhou XH, Zhang J, Zhou YX, Ying J, Wu GQ and Qian JH: Propofol promotes cell apoptosis via inhibiting HOTAIR mediated mTOR pathway in cervical cancer. Biochem Biophys Res Commun 468: 561-567, 2015.

18. Lv XB, Lian GY, Wang HR, Song E, Yao H and Wang MH: Long noncoding RNA HOTAIR is a prognostic marker for esophageal squamous cell carcinoma progression and survival. PLoS One 8: e63516, 2013.

19. Ding C, Cheng S, Yang Z, Lv Z, Xiao H, Du C, Peng C, Xie H, Zhou L, Wu J and Zheng S: Long non-coding RNA HOTAIR promotes cell migration and invasion via down-regulation of RNA binding motif protein 38 in hepatocellular carcinoma cells. Int J Mol Sci 15: 4060-4076, 2014.

20. Yang Z, Zhou L, Wu LM, Lai MC, Xie HY, Zhang F and Zheng SS: Overexpression of long non-coding RNA HOTAIR predicts tumor recurrence in hepatocellular carcinoma patients following liver transplantation. Ann Surg Oncol 18: 1243-1250, 2011.

21. Dong M, Yang G, Liu H, Liu X, Lin S, Sun D and Wang Y: Aged black garlic extract inhibits HT29 colon cancer cell growth via the PI3K/Akt signaling pathway. Biomed Rep 2: 250-254, 2014.

22. Mediani L, Gibellini F, Bertacchini J, Frasson C, Bosco R, Accordi $\mathrm{B}$, Basso G, Bonora M, Calabrò ML, Mattiolo A, et al: Reversal of the glycolytic phenotype of primary effusion lymphoma cells by combined targeting of cellular metabolism and PI3K/Akt/ mTOR signaling. Oncotarget 7: 5521-5537, 2016.

23. Ochi $\mathrm{E}$, Ishii $\mathrm{N}$ and Nakazato K: Time course change of IGF1/Akt/mTOR/p70s6k pathway activation in rat gastrocnemius muscle during repeated bouts of eccentric exercise. J Sports Sci Med 9: 170-175, 2010

24. Li J, Li X, Xu W, Wang S, Hu Z, Zhang Q, Deng X, Wang J, Zhang J and Guo C: Antifibrotic effects of luteolin on hepatic stellate cells and liver fibrosis by targeting AKT/mTOR/p70S6K and TGFbeta/Smad signalling pathways. Liver Int 35: 1222-1233, 2015.

25. Pratheeshkumar P, Budhraja A, Son YO, Wang X, Zhang Z, Ding S, Wang L, Hitron A, Lee JC, Xu M, et al: Quercetin inhibits angiogenesis mediated human prostate tumor growth by targeting VEGFR- 2 regulated AKT/mTOR/P70S6K signaling pathways. PLoS One 7: e47516, 2012.

26. Saraswati S, Kumar S and Alhaider AA: $\alpha$-santalol inhibits the angiogenesis and growth of human prostate tumor growth by targeting vascular endothelial growth factor receptor 2-mediated AKT/mTOR/P70S6K signaling pathway. Mol Cancer 12: 147, 2013.

27. Li SY, Fang CX, Aberle NS II, Ren BH, Ceylan-Isik AF and Ren J: Inhibition of PI-3 kinase/Akt/mTOR, but not calcineurin signaling, reverses insulin-like growth factor I-induced protection against glucose toxicity in cardiomyocyte contractile function. J Endocrinol 186: 491-503, 2005.

28. Zhang L, Wang H, Xu J,Zhu J and Ding K: Inhibition of cathepsin S induces autophagy and apoptosis in human glioblastoma cell lines through ROS-mediated PI3K/AKT/mTOR/p70S6K and JNK signaling pathways. Toxicol Lett 228: 248-259, 2014. 